\title{
Life in Seas Frozen and Tropical FOR PENGUINS AND BEYOND, NEW DISCOVERIES IN OCEAN GENOMICS
}

By Cheryl Lyn Dybas, Photos by llya Raskin

\section{WHEN ARE TWO PENGUIN SPECIES FOUR?}

It's autumn in the Northern Hemisphere, but far, far to the south, austral spring is just beginning to poke its way through the ice. Life is still in a deep freeze, including for what may be the Southern Hemisphere's best-known ambassadors, penguins.

The evolutionary history of penguins, most of which live in iceboxes, is a tale of success. Earth is home to 18 species of these waddling, flightless seabirds. Or so scientists thought. Now biologists are asking: When viewed through the lens of genomics, how many penguin species in fact exist?

Take gentoo penguins. Gentoos are most closely related to Adélie and chinstrap penguins, with two gentoo subspecies recognized: Pygoscelis papua (the subAntarctic gentoo) and Pygoscelis papua ellsworthi (the Antarctic gentoo).

After analyzing the genetic differences in gentoo populations, however, scientists at the University of Bath say the penguins should be reclassified as four species. The researchers suggest that the two current subspecies should be raised to species level, and that two new species should be named: $P$. poncetti and P. taeniata.

The study, published in October 2020 in Ecology and Evolution, looked at the genomes of gentoos on the Falkland Islands and South Georgia Island, as well as gentoos on the South Shetland Islands and Kerguelen Islands. The biologists used genomic data to create an evolutionary tree, then combined that with measurements from museum specimens.

"All the discoveries of the marine biologists, however remote they may now seem from practical issues, will be required in their different ways for a full understanding of the life in the sea and its more rational exploitation."

- Sir Alister Hardy, The Open Sea: Its Natural History

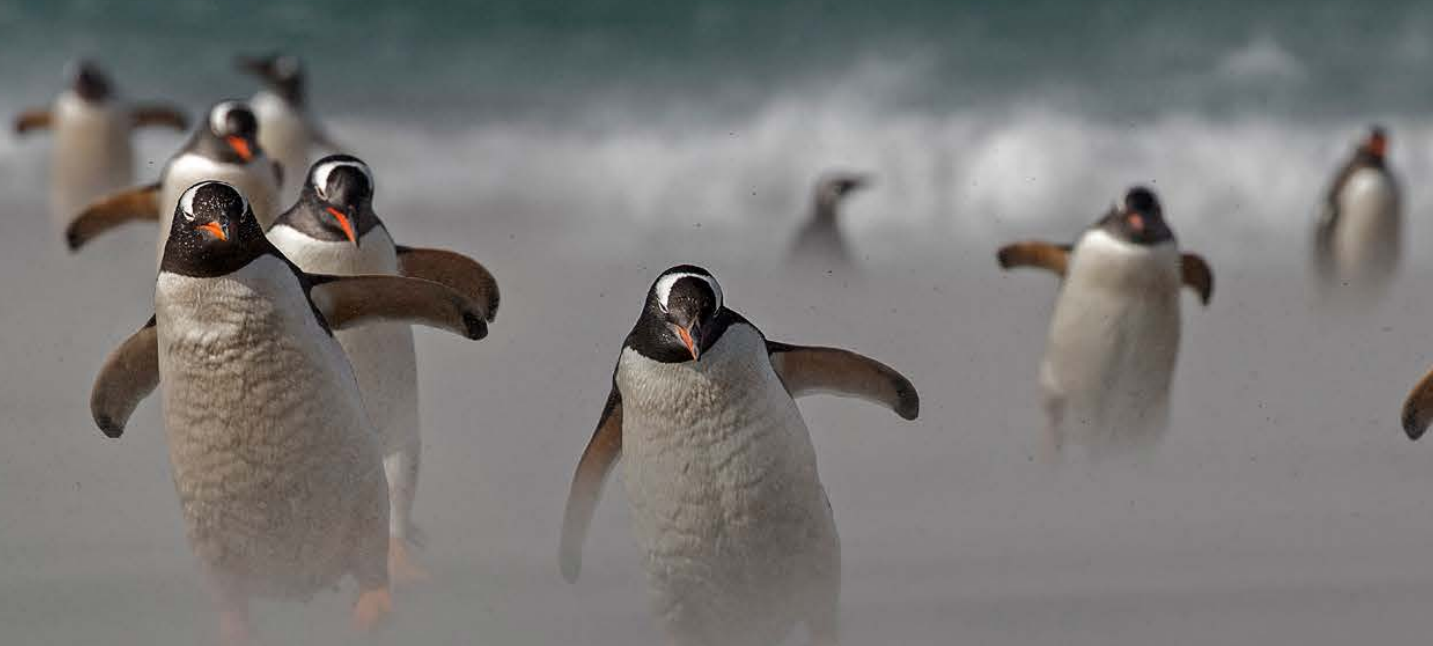

Gentoo penguins (Pygoscelis papua) coming

onto the beach in the Falkland Islands. 


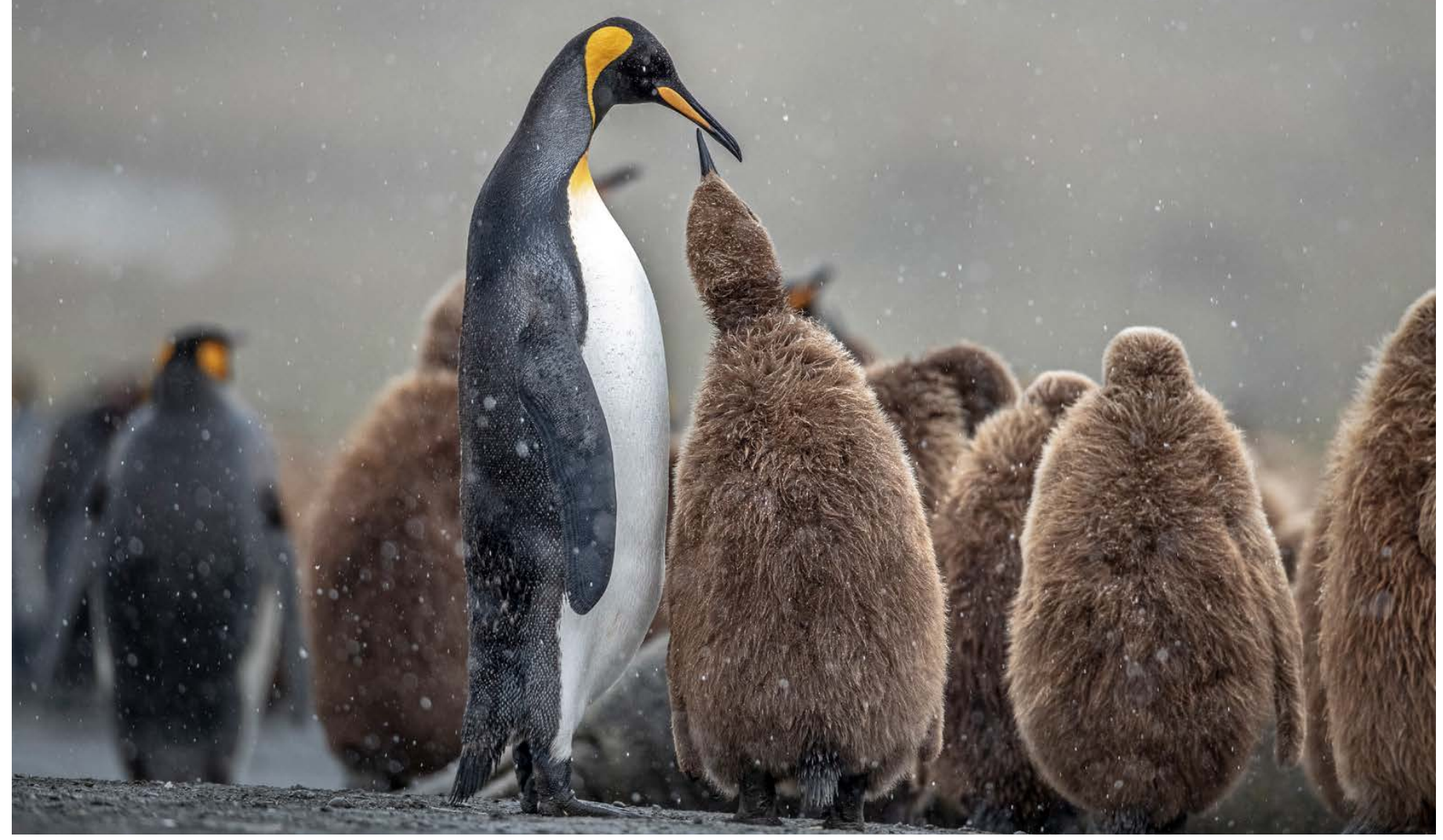

Adult and juvenile king penguins (Aptenodytes patagonicus) on South Georgia Island.

"These penguins are not only genetically distinct, they are physically different, too," says Jane Younger of the University of Bath, who led the project. "Gentoos tend to stick close to their home colonies, and over hundreds of thousands of years have become geographically isolated from each other to the point that they don't interbreed."

The four possible gentoo species live in different latitudes-P. ellsworthi on the Antarctic continent and $P$. poncettii, $P$. taeniata, and $P$. papua farther north where conditions are milder. It's a similar story to giraffes, the biologists say, which in 2016 were revealed as four genetically distinct species.

As four gentoo species, the penguins would be better protected, the researchers believe. A decline in one species would change its threat status as defined by the IUCN (International Union for Conservation of Nature) Red List, which shows trends in extinction risk. "Currently gentoo penguins are fairly stable," says Younger, "but there's evidence that northern populations are moving south as climate gets warmer. We need to watch these changes closely."

\section{MARCH OF THE PENGUIN GENOMES}

Enter scientists affiliated with the Penguin Genome Consortium. The researchers are sequencing all living penguin species' genomes to understand the evolution of life on the ice.

Their September 2019 paper in the journal GigaScience is the first effort to capture the genomic landscape of all living penguin species. The consortium-made up of investigators from China, Denmark, New Zealand, Australia, Argentina, South Africa, the UK, and other nations-has produced penguin genome sequences for extant penguin species. The work is furthering research in areas from evolution to the impact of human activities and environmental changes.

With penguins' specialized skin and feathers and an enhanced thermoregulation systems, they span the Southern Hemisphere from the tropical Galápagos Islands, to the temperate forests of New Zealand, to the extreme cold of the rocky coastlines of the sub-Antarctic islands and the sea ice around Antarctica. This iconic bird group long ago transitioned from flying seabirds to powerful, flightless marine divers.

Despite those adaptations, penguin populations have experienced rapid declines in recent decades, some with extreme population drops, such as the crash of king penguins. The species has declined by $88 \%$ in three decades.

Dwindling penguin numbers have been linked to climate change, environmental degradation, exploitation of the marine environment, fisheries bycatch, pollution, and the introduction of exotic predators. The genome sequences of penguin species alive today are resources for understanding the losses, the paper's coauthors say.

"The population histories of penguin species can be seen in their genomes," says coauthor Theresa Cole of the University of Otago in New Zealand. "The research will help us understand how future climate change may affect these and other species and help us develop conservation strategies."

\section{PROMISE OF THE OCEAN GENOME}

Far beyond penguins, the sea is home to remarkable biodiversity. "The genetic biodiversity we see on land is a tiny fraction of that in the ocean," says Rachel Wynberg, a member of the High Level Panel for a Sustainable Ocean Economy 


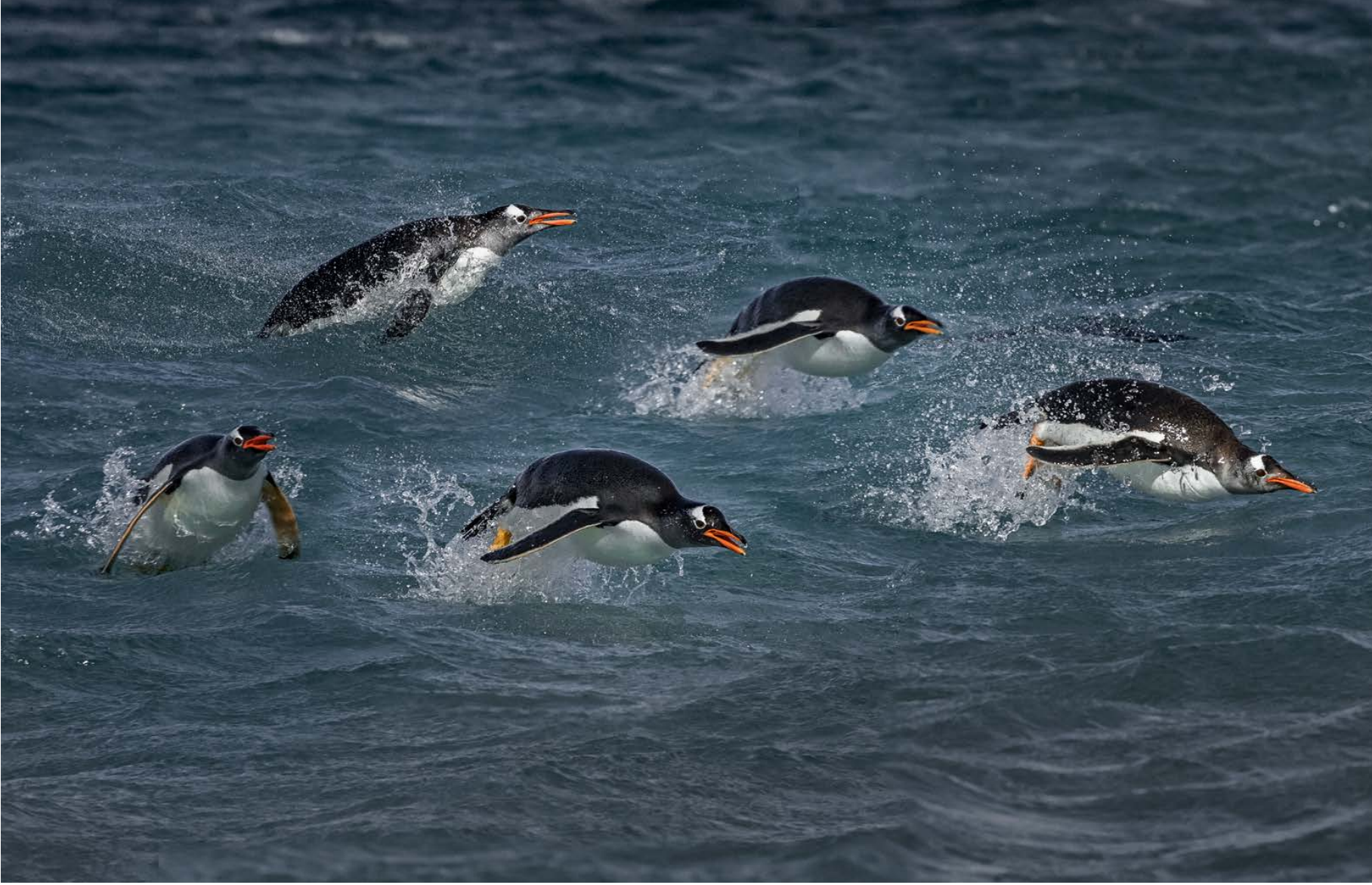

Gentoo penguins porpoising off the Falkland Islands.

and an environmental scientist at South Africa's University of Cape Town. Only $35 \%$ of major animal phyla are found on land, according to "The Ocean Genome: Conservation and the Fair, Equitable and Sustainable Use of Marine Genetic Resources," a paper released in June 2020 by the High Level Panel.

Established in September 2018, the High Level Panel is an initiative of 14 heads of government from Australia, Canada, Chile, Fiji, Ghana, Indonesia, Jamaica, Japan, Kenya, Mexico, Namibia, Norway, Palau, and Portugal.

The ocean genome-the genetic material in all marine biodiversity, or the complete set of genes in every cell or organism in the sea-is the foundation on which marine ecosystems rest. "The ocean genome determines the abundance and resilience of biological resources, including fisheries and aquaculture, which collectively form a pillar of global food security and human well-being," states the 2020 High Level Panel paper.

Untold benefits are hidden in the sea's genetic diversity, scientists believe. For example, the COVID-19 pandemic has drawn renewed attention to the ocean genome, a source of hydrothermal vent bacteria that produce enzymes important in virus testing. "When it comes to the ways humans rely on the ocean, genetic biodiversity, what we call the marine genome, provides a treasure trove of helpful products such as food and medicines," says Wynberg.

A paper Wynberg coauthored with Robert Blasiak of Stockholm University and other scientists, published in Nature Sustainability in May 2020, states that, "conserving [marine] genetic diversity helps foster the fitness of populations and their potential to recover from and adapt to threats ranging from disease to environmental changes."

\section{HEYDAY OF OCEAN GENOMICS?}

The heyday of ocean genomics research may be on the horizon. Marine conservation initiatives based on genomics are "nascent but show tremendous promise," states the 2019 report Ocean Genomics Horizon Scan. "While sequencing costs continue to plummet, it is expensive and difficult to mimic marine systems in laboratory settings. There is a great need to build genetic libraries and molecular toolkits to understand the processes driving the sustainability of ocean life."
One year later in this fast-moving field, the 2020 document Microbial Genomics of the Global Ocean System reports that researchers are beginning to "wield a toolbox of 'omics technologies and bioinformatic methods that allow them to probe the structure and function of microbial [and other] communities that form the foundation of marine ecosystems." These technologies range from genomics to transcriptomics, to proteomics, to metabolomics and are being used to study countless species.

More than a half-century after the 1965 publication of The Open Sea: Its Natural History, Sir Alister Hardy couldn't have imagined ocean genomics as we know it today-and where it could lead, including to redefined taxonomy and insights into a virus that's ricocheting around the globe. @

\section{ABOUT THE AUTHOR}

Cheryl Lyn Dybas (cheryl.lyn.dybas@gmail.com), a Fellow of the International League of Conservation Writers, is a contributing writer for Oceanography and a marine ecologist. She also writes about science and the environment for National Geographic, BioScience, National Wildlife, Natural History, Ocean Geographic, ON Nature, and many other publications. 